\title{
Role of Digital Subtraction Fluoroscopic Imaging in Detecting INTRAVASCULAR INJECTIONS
}

\author{
Joseph F. Jasper, MD
}

Complications of unintended intravascular penetration and subsequent injection of local anesthetics and/or other drugs occasionally are devastating. Multiple reports have related to unrecognized intravascular placement of the needle. The generally accepted technique during interventional techniques is intermittent fluoroscopy. In fact, this may miss vascular uptake due to rapid washout. Thus, digital subtraction, the commonly accepted standard for docu- menting angiography and venography, may be a useful tool for documentation of and/or avoidance of intravascular placement of the needle and subsequent injections with interventional techniques.

This case report involves description of digital subtraction to enhance visualization of contrast distribution during injection. Three series of images are included from at lanto-occipital joint, caudal epidural catheterization, and a cervical transforaminal in jection.

The case reports demonstrate that digital subtraction fluoroscopic imaging is superior to intermittent or live fluoroscopy in detecting intravascular injections with interventional techniques.

Keywords: Interventional techniques, intravascular injection, fluoroscopy, imaging, digital subtraction, digital subtraction fluoroscopic imaging
Recent concern regarding complications of transforaminal cervical epidural steroid injections with cord infarction and other devastating neurological consequences continues to emerge (1-5). Multiple authors have described unrecognized intravascular injections (6-12). The technique of injecting contrast and then stepping back and taking the $\mathrm{x}$-ray will frequently miss vascular uptake due to rapid washout. Digital subtraction is the commonly accepted standard for documenting angiography and venography. Detection of arterial injection in particular by digital subtraction may provide a sensitive warning sign to the spinal injectionist. Several physicians involved in expert witness testimony have alerted interventional pain physicians to the fact that devastating complications of transforaminal and other spinal injections commonly employed by the interventional pain physician may result in paralysis or death (13). Forty to 50 such cases are known to have occurred over the past couple of years worldwide $(2-5,13)$.

There is a current lack of sufficient

From Advanced Pain Medicine Physicians, Tacoma, Washington. Address Correspondence: Joseph F. Jasper, MD, 1628 South Mildred Street, Suite \#105, Tacoma, WA 98465-1613. E-mail: apmedicine@qwest.net.

Funding: There was no external funding in preparation of this manuscript. histopathologic and statistical data to understand the mechanism of such injuries. Several potential contributing factors have been proposed, but there is limited support for any of these theories. Common to most of these factors is the mechanism of intravascular injection. Intravascular injection may lead to infarction or neural toxicity. Proposed factors contributing to this are sharp versus blunt needles, size of the needle, particulate versus non-particulate corticosteroids, pressure and/or rate of injection, positioning of the needle tip within the foramen, vascular engorgement, foraminal stenosis, post-injection epidural hematoma, epidural or perineural fibrosis, and inability to recognize vascular injection with commonly employed fluoroscopic guidance techniques (2-12, $13,14)$. By enhancing the ability to recognize intravascular injection utilizing digital subtraction fluoroscopy and live injection observation, the frequency of such devastating neurological complications theoretically might be reduced. Over the past year this investigator has used digital subtraction to enhance visualization of contrast distribution during injection and has been impressed that plain fluoroscopy frequently misses both venous and arterial injection, which is often revealed with digital subtraction. This manuscript describes role of digital fluoroscopic imaging in interventional pain management with 3 case reports.

\section{CASE Reports}

The following images were obtained during spinal injection using an OEC 9800 with digital subtraction capability . The machine was set to subtraction. Two choices were available: create subtraction movies with the right pedal or spot images with the left pedal. With either, the machine will subtract pixel values of an initial scout image pre-injection mask from subsequent images following contrast injection. In theory, the image would only reveal the contrast. Generally, slight patient movement often provides a ghostly skeletal background. At times incomplete subtraction due to patient movement may

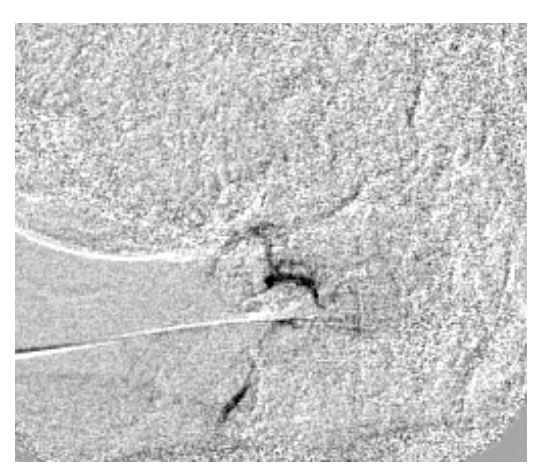

Fig 1. Digital subtraction image of vascular filling pattern during attempted entry into atlanto-occipital joint 


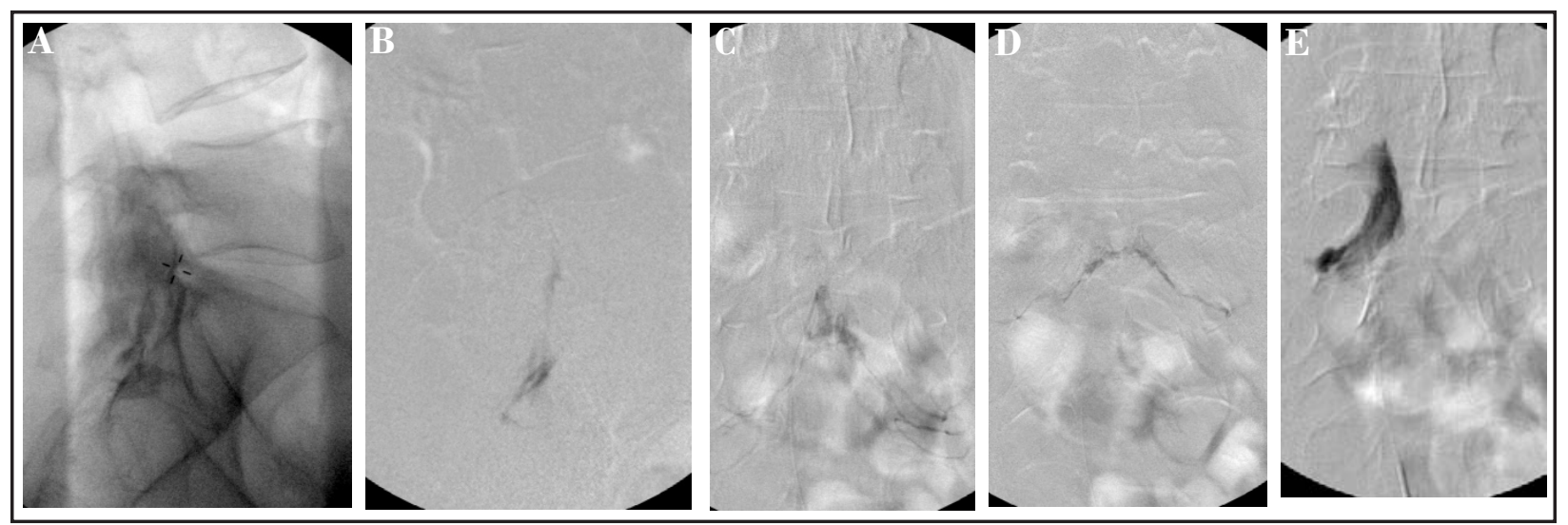

Fig 2. Caudal Injection with catheter: Figure 2 a failed to demonstrate significant contrast accumulation after $3 \mathrm{~mL}$ of Omnipaque 300 injection. Repeat injection in a lateral view (Fig. 2b) and followed by a posterior-anterior view with additional injection of $2 \mathrm{~mL}$ of contrast (Fig. 2c) revealed distinct vascular flow with washout as one observes live continuous subtraction. Subsequent catheter pullback and reintroduction at first presented with a slightly different intravascular pattern (Fig. 2d). The final placement produced the desired L5-S1 result shown in Figure 2 e.

yield confusing shadows or highlights.

The first series demonstrates an attempted intraarticular entry of atlantooccipital joint, Thus, during atlanto-occipital joint injection the vertebral artery may be encountered. Figure 1 demonstrates vascular pattern flow during attempted entry into atlanto-occipital joint. This injection was discontinued.
The second series is from a caudal with directional catheter. The first lateral plain film Figure 2a failed to demonstrate significant contrast accumulation after 3 $\mathrm{mL}$ of Omnipaque 300 injection. Repeat injection in a lateral view (Fig. 2b) and followed by a posterior-anterior view with additional injection of $2 \mathrm{~mL}$ of contrast (Fig. 2c) revealed distinct vascular flow with washout as one observes live continuous subtraction. Subsequent catheter pullback and reintroduction at first presented with a slightly different intravascular pattern (Fig. 2d). The final placement produced the desired L5-S1 result shown in Figure 2e.

The third series is a cervical transforaminal injection. The needle tip was
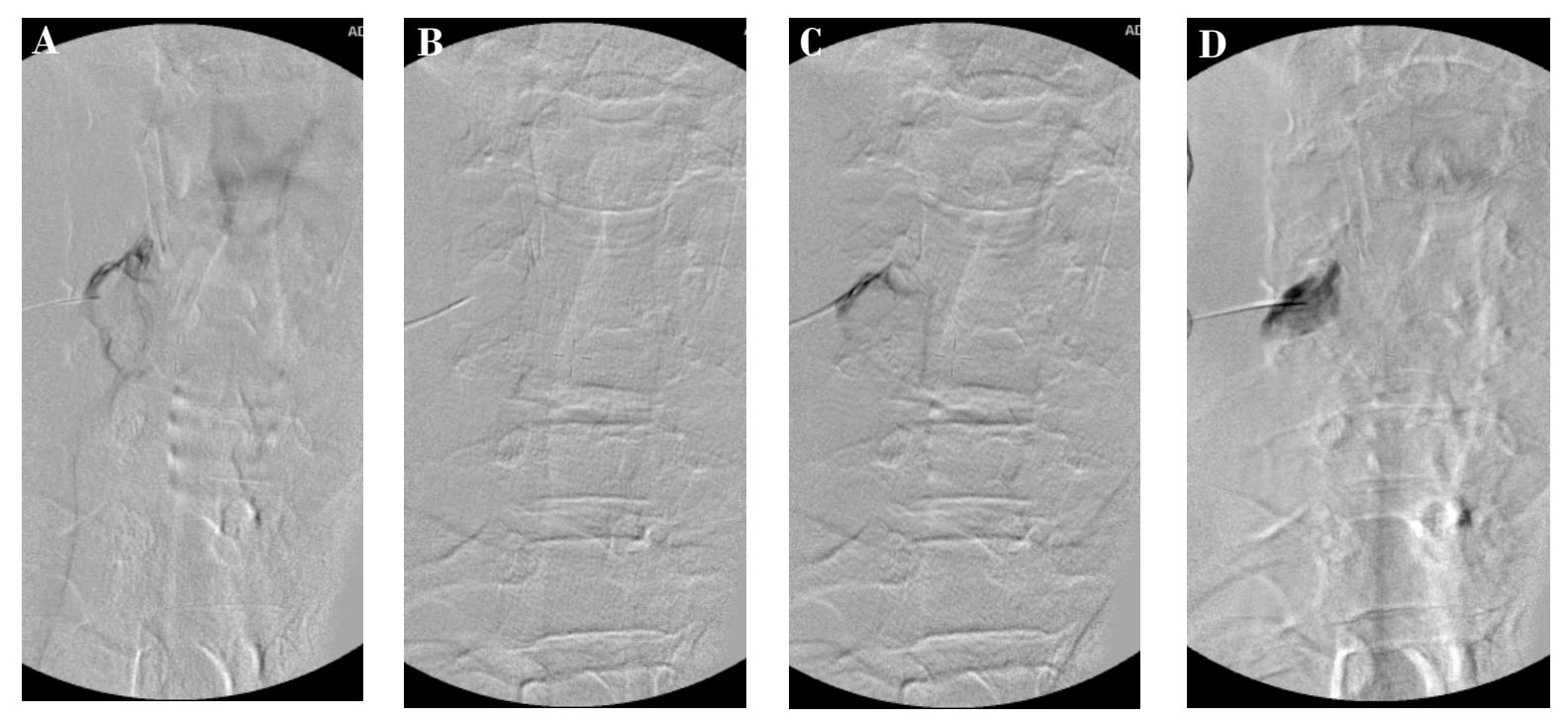

Fig 3. Cervical transforaminal injection: Venous injection was obvious as seen in Figure 3a. Within a few seconds this completely disappeared as shown in Figure 3b. With a slight needle adjustment in Figure 3c partial perineural flow pattern that appears inadequate on this still image was actually primarily vascular on live injection. Final proper contrast spread as seen in Figure $3 d$. 
placed glancing along the bone of the superior articular process just below the joint line about mid level. Venous injection was obvious as seen in Figure $3 \mathrm{a}$. Within a few seconds this completely disappeared as shown in Figure $3 \mathrm{~b}$. Thus, one injecting, stepping back and looking would only have seen the lack of contrast accumulation, but miss the vascular flow. With a slight needle adjustment partial perineural flow pattern that appears inadequate on this still image was actually primarily vascular on live injection, again proving the need to inject live with the fluoro. Final needle repositioning resulted in proper contrast spread as seen in Figure 3d.

\section{DISCUSSION}

The vascular supply of the lumbar spine, spinal nerves and cord are well described in Clinical Anatomy of the Lumbar Spine and Sacrum by Bogduk (15). The venous system is valveless (16). In the upper cervical spine this communicates with the sinuses of the cranium and thus brain, as well as radicular and spinal venous plexi. Throughout the spine the venous plexi are extensive both intra and extraspinally. Venous injection is a risk with more than transforaminal techniques, and could occur with sympathetic blocks and interlaminar injections. Thus a high-pressure inadvertent venous injection may result in CNS toxicity. The radicular and collateral radicular arteries may also be prone to inadvertent injection and thus endanger the cord or segmental nerves with infarction or toxicity. Dilation of veins occurs in the region of spinal pathology (13) creating a higher potential for inadvertent venipuncture.

As digital subtraction can provide a more sensitive warning of vascular injection, it would seem prudent for the spinal injectionist to avail himself of that when available. Digital subtraction is not universally available to spinal injectionists and not the current standard of practice. No data is likely to come forward to support the contention that digital subtraction reduces the risk of neurological disasters from injections because the incidence appears low; a prospective and randomized study of any injection standard change would likely require 100,000 subjects or more to gain statistical meaning.

Disadvantages of the digital subtraction fluoroscopic imaging adds to radia- tion exposure to the patient, physician and staff. The cost of adding the digital subtraction to a new purchase or to upgrade an existing fluoro unit is not high, but will not likely be compensated. The cost of an entry level digital subtraction package would be approximately 15 thousand to 18 thousand dollars above the base cost of a good c-arm.

Beyond intravascular injection, other complications of spinal injection may cause neurologic sequellae such as intramedullary injection of the cord (17), cardiorepiratory cardiorespiratory arrest (18), and epidural or subdural hematoma (19-21) or abscess (22-24), or from medication errors (25). Many such complications are delayed by hours from the time of injection. Physicicans must fully consent our patients including the risks of devastating neurologic complications with spinal injections, and then apply our best prudent practice to reduce risks to a minimum. It has been previously proposed that digital subtraction fluoroscopy may be a useful tool for documentation of epidural contrast spread and perhaps discography (26). When contrast patterns are different from expected, the possibility that one is injecting into unintended conduits or structures should warn the injectionist to reassess and reposition the needle or catheter. Digital subtraction may add to the resolution of such assessment. This presentation may add further weight to the value of digital subtraction as a valuable tool for the interventional pain physician.

\section{Conclusion}

Recent concern regarding complications of transforaminal epidural steroid injections with devastating neurological consequences is justifiable. The accepted technique of intermittent injection of contrast with intermittent fluoroscopy appears to frequently miss vascular uptake due to rapid washout. Digital subtraction fluoroscopic imaging, commonly utilized in documentation of angiography and venography, may be utilized in interventional pain management to enhance detection of intravascular placement of the needle and injections. Thoght likely impractical, large scale controlled trials would be required to prove the role of digital subtraction fluoroscopic imaging in interventional pain management.

\section{Author Affiliation: \\ Joseph F. Jasper, MD \\ Medical Director \\ Advanced Pain Medicine Physicians \\ 1628, South Mildred Street, Suite\#105 \\ Tacoma, WA 98465-1613 \\ E-mail: apmedicine@qwest.net}

\section{REFERENCES:}

1. Baker R, Dreyfus P, Mercer S et al. Cervical transforaminal injection of corticosteroids into a radicular artery: A possible mechanism for spinal cord injury. Pain 2003; 103:211-215.

2. Houten JK, Errico TJ. Paraplegia after lumbosacral nerve root block: Report of three cases. The Spine Journal 2002; 2:70-75.

3. Brouwers PJ, Kottink EJ, Simon MA et al. A cervical anterior spinal artery syndrome after diagnostic blockade of the right C6nerve root. Pain 2001; 91:397-399.

4. Nash TP, Brouwers PJ, Ella JB et al. Comment on A cervical anterior spinal artery syndrome after diagnostic blockade of the right C6-nerve root. Pain 2001; 91:217218.

5. Nelson JW. Letter to the Editor. In response to Houten JK, Errico TJ. Paraplegia after lumbosacral nerve block. Spine J 2003; 2:88-89.

6. Sullivan WJ, Willick SE, Chira-Adisai W et al. Incidence of intravascular uptake in lumbar spinal injection procedures. Spine 2000; 25:481-486.

7. Furman MB. Incidence of intravascular uptake in transforaminal lumbar epidural steroid injections. Spine 2000; 25:26282632.

8. Botwin KP, Gruber RD, Bouchlas CG et al. Complications of fluoroscopically guided transforaminal lumbar epidural injections. Arch Phys Med Rehabil 2000; 81: 1045-1050.

9. Renfrew DL, Moore TE, Kathol MH, et al: Correct placement of epidural steroid injections: Fluoroscopic guidance and contrast administration. AJNR 1991; 12:10031007.

10. White AH, Derby R, Wynne G. Epidural injections for the diagnosis and treatment of low-back pain. Spine 1980; 5:78-86.

11. Manchikanti L, Bakhit CE, Pampati V. Role of epidurography in caudal neuroplasty. Pain Digest 1998; 8:277-281.

12. Furman MB, Giovanniello MT, O’Brien EM. Incidence of intravascular penetration in transforaminal cervical epidural steroid injections. Spine 2003; 28:21-25.

13. Racz GB, Manchikanti L, Schultz D, Kloth D, Dunbar E, Trescot A, Helm S, Hansen HC, Jasper JF. Discussion on Safety of Interventional Techniques. ASIPP's Cadaver 
Workshop, Memphis, TN, October 25-27, 2002, May 17-18, 2003.

14. Stoll A, Sanchez M. Epidural hematoma after epidural block: Implications for its use in pain management. Surg Neurol 2002 57:235-240.

15. Bogduk N. Clinical Anatomy of the Lumbar Spine and Sacrum Third Edition. Churchill Livingstone, 1997.

16. Grant JCB. Grant's Atlas of Anatomy. Williams \& Wilkins. 1972 illustrations and text 390, 493.

17. Simon SL, Abrahams JM, Sean Grady M et al. Intramedullary injection of contrast into the cervical spinal cord during cervical myelography: a case report. Spine 2002, May 15:27:E274-277

18. Silva Costa-Gomes T, et al. Cardiorespi- ratory arrest: a rare complication of subdural block[Spanish; English abstract reviewed] Rev Esp Anesthesiol Reanim 2002 Feb; 49(2):108-111

19. Stoll A, Sanchez M. Epidural hematoma after epidural block: implication for its use in pain management. Surg Neurol 2002 Apr;57(4):235-240

20. Reitman CA, Watters W. Subdural hematoma after cervical epidural steroid injection. Spine 2002 Mar 15;27:E174-176

21. Wildforster U, Schregel W, Harders A. Delayed lumbar epidural hematoma. Discussion of the risk factors: hypertension, anticoagulation and spinal anesthesia. [German; English abstract reviewed] Anasthesiol Intensivmed Notfallmed Shmerzther 1998 Aug;33(8):517-520
22. Abram SE, O'Connor TC. Complications associated with epidural injections. Reg Anesth 1996 Mar-Apr;21(2):149-162

23. Knight JW, Cordingley JJ, Palazzo MG. Epidural abscess following epidural steroid and local anaesthetic injection. Anaesthesia 1997 Jun;52:576-578

24. Koka VK, Potti A. Spinal epidural abscess after corticosteroid injections. South Med J 2002 Jul;95(7);772-774

25. Jones TF, et al. Neurologic complications including paralysis after a medication error involving implanted intrathecal catheters. Am J Med 2002 Jan;112(1):31-36

26. Jasper JF. Is Digital Subtraction Fluoroscopy a Useful Tool for the Interventional Pain Physician? Pain Physician 2002, 5:36-39 